\title{
Is Pulmonary Artery Regurgitation the Knight in Shining Armor for a Young Adult Patient With Congenital Aortopulmonary Window?
}

\author{
Aurora Bakallia ${ }^{\mathrm{a}}$ Kelmend Pallaska ${ }^{\mathrm{a}, \mathrm{b}}$, Faik Shatri ${ }^{\mathrm{a}}$, Xhevdet Krasniqi ${ }^{\mathrm{a}}$, \\ Edita Pllana $^{\text {a }}$, Krenare Limani ${ }^{\mathrm{a}}$
}

\begin{abstract}
Aortopulmonary window in adults without signs of heart failure or pulmonary hypertension is exceptionally rare. We report here a case of a 27-year-old Caucasian male patient who presented with ventricular tachycardia and loud laterosternal systolic murmur due to a $9 \mathrm{~mm}$ aortopulmonary septal defect type 1, diagnosed for the first time. Echocardiography examination also revealed moderate pulmonary artery regurgitation. Pulmonary artery regurgitation may have served as the knight in shining armor in this extremely rare asymptomatic adult patient with aortopulmonary window, since a large amount of blood that enters the pulmonary trunk from the aorta redirects toward the right ventricle. Ventricular tachycardia may be the sole clinical presentation in an adult patient with aortopulmonary window and moderate pulmonary window.
\end{abstract}

Keywords: Aortopulmonary window; Pulmonary regurgitation; Adult patient; Ventricular tachycardia

\section{Introduction}

Aortopulmonary window is a particularly rare congenital disorder in adult patients since if untreated it commonly leads to mortality during infancy or childhood [1].

We report here an exceptionally rare case of a 27 -yearold male patient with aortopulmonary window without signs of heart failure or pulmonary hypertension, diagnosed for the first time. The value of this case presentation is that it is extremely rare for an adult with aortopulmonary window not to develop heart failure or pulmonary vasculature disease; and in this presentation we strive to explain the mechanism responsible for this positive outcome. To our best knowledge this is

Manuscript submitted July 8, 2018, accepted August 13, 2018

${ }^{a}$ Clinic of Cardiology, University Clinical Center of Kosova, Prishtine, Kosovo, Albania

${ }^{\mathrm{b}}$ Corresponding Author: Kelmend Pallaska, Clinic of Cardiology, University Clinical Center of Kosova, Prishtine, Kosovo, Albania.

Email: kelipall@yahoo.com;

doi: https://doi.org/10.14740/jmc3125w the oldest asymptomatic patient with aortopulmonary window reported in the medical literature.

\section{Case Report}

We report here a case of a 27 -year-old male patient who was admitted to our Cardiology Clinic due to palpitations and fatigue. He reported that he was active without major complaints until the palpitations began. He possessed medical documentation of early childhood from a different medical center that described a systolic murmur as a result of ventricular septal defect (VSD), which was not treated. The size and site of VSD were not described. Patient has not been visited by cardiologist since then. He has family history of congenital heart disease, as his mother was diagnosed with atrial septal defect and has been operated recently.

Physical examination of the heart revealed a harsh systolic murmur VI/VI, with punctum maximum at the left sternal border, at the third intercostal space. Patient was not cyanotic, and clubbing was not present. He had a baseline saturation of $98 \%$, and his blood pressure was $120 / 80 \mathrm{~mm} \mathrm{Hg}$. Patient was $178 \mathrm{~cm}$ tall and weighed $68 \mathrm{~kg}$. Laboratory results were within reference range.

ECG at admission showed right ventricular outflow tract sustained ventricular tachycardia (Fig. 1). Following ventricular tachycardia resolution, ECG demonstrated sinus rhythm, heart rate of 85 per minute, normal heart axis.

Transthoracic echocardiography revealed an aortopulmonary septal defect type 1, visualized in both long axis and short axis parasternal views by 2D, Doppler and color-Doppler (Fig. 2a-c). The aortopulmonary window was $9 \mathrm{~mm}$ in diameter, with $7 \mathrm{~m} / \mathrm{s}$ velocity across the defect and this is strongly believed to be the cause of the loud systolic murmur (Fig. 3). Moderate pulmonary artery regurgitation was also detected (Fig. 2c). Heart chambers were not dilated and left and right ventricular function was within normal reference range. Tricuspid regurgitation was not seen, whereas pulmonary artery acceleration time was 105 ms. Pulmonary trunk diameter, measured at short axis parasternal view was $22 \mathrm{~mm}$. Mild anterior leaflet mitral valve prolapse with trivial mitral regurgitation and mild aortic regurgitation were also seen. Ventricular septal defect was not detected.

He was treated with amiodarone, for ventricular tachycardia, according to the guidelines and aspirin. 


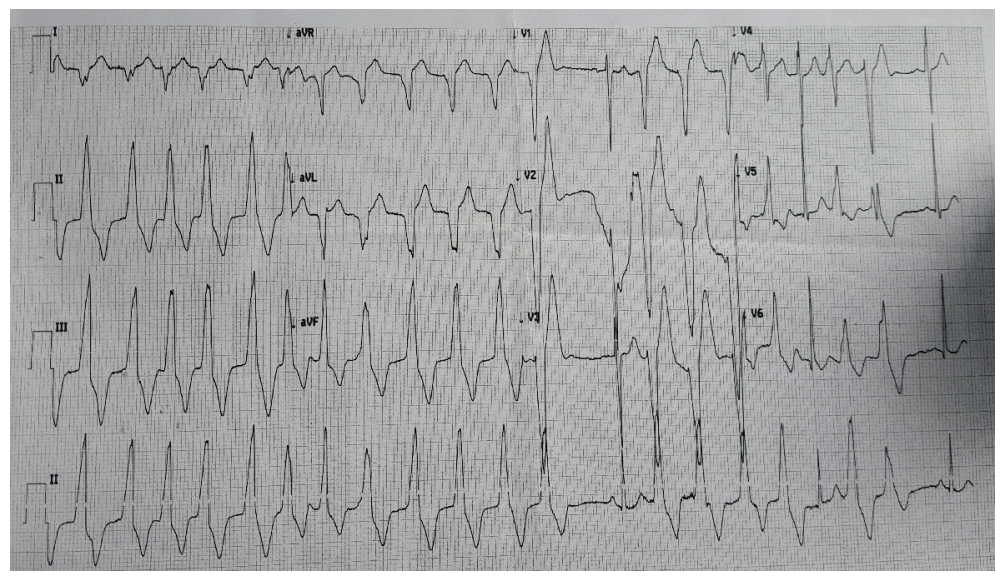

Figure 1. ECG at admission demonstrating right ventricular outflow tract ventricular tachycardia.

Patient refused to undergo additional examinations to confirm the diagnosis. At hospital discharge, he no longer had palpitations nor there were changes on ECG consistent with arrhythmias and he was feeling better.

\section{Discussion}

Aortopulmonary window, a communication between ascending aorta and pulmonary trunk in the presence of two separate semilunar valves, causes a left to right shunt which leads to heart failure and pulmonary hypertension that usually evolves rapidly to pulmonary vascular disease. Surgical correction is indicated in all cases as soon as this disorder is diagnosed. If not surgically corrected, mortality is around $40 \%$ in the first year of life [2]. Thus, there are limited reports in medical literature of adults with aortopulmonary window [1, 3-6]. It is exceptionally rare for heart failure or pulmonary vascular disease not to develop in an adult with aortopulmonary window, as it is the case with our patient. We believe that two factors may have contributed to our patient's condition. Firstly, the defect size was not very large, although it is not a size to be underestimated. Secondly but more importantly, we believe that the main saviour for our patient was the moderate pulmonary artery regurgitation, as a large amount of the blood that enters the pulmonary artery trunk from aorta redirects to the right ventricle, thus not overloading the pulmonary vasculature. On the other hand, pulmonary regurgitation is well tolerated as it is a slow developing process, presenting with symptoms in $6 \%$ at 20 years of age and $20 \%$ by 40 years [7]. Pulmonary regurgitation is frequently manifested with ventricular tachycardia [8], which may be the reason of ventricular tachycardia in our patient. Right ventricular dilatation due to pulmonary regurgitation is believed to be responsible for rhythm disturbances. In our case right ventricle size and function were still within normal reference range; however, pulmonary regurgitation jet, redirecting to the right ventricle a considerable amount of the high velocity flow arriving from aorta, may have been hitting the right ventricular outflow tract constantly thus provoking right ventricular tachycardia.

VSD diagnosed in childhood in our patient may have closed spontaneously, as it is not detected currently. However, the similarity of the murmur produced by VSD and aortopulmonary window may have satisfied, at that time, the physician with the diagnosis of VSD thus failing to notice the aortopulmonary window. Aortopulmonary windows are often misdiagnosed or overlooked, although as long as this very rare malformation it is kept in mind it can be easily diagnosed by echocardiography [9]. Furthermore, aortopulmonary window is known to be associated with other congenital cardiac disorders such as coarctation of aorta, tetralogy Fallot, transposition
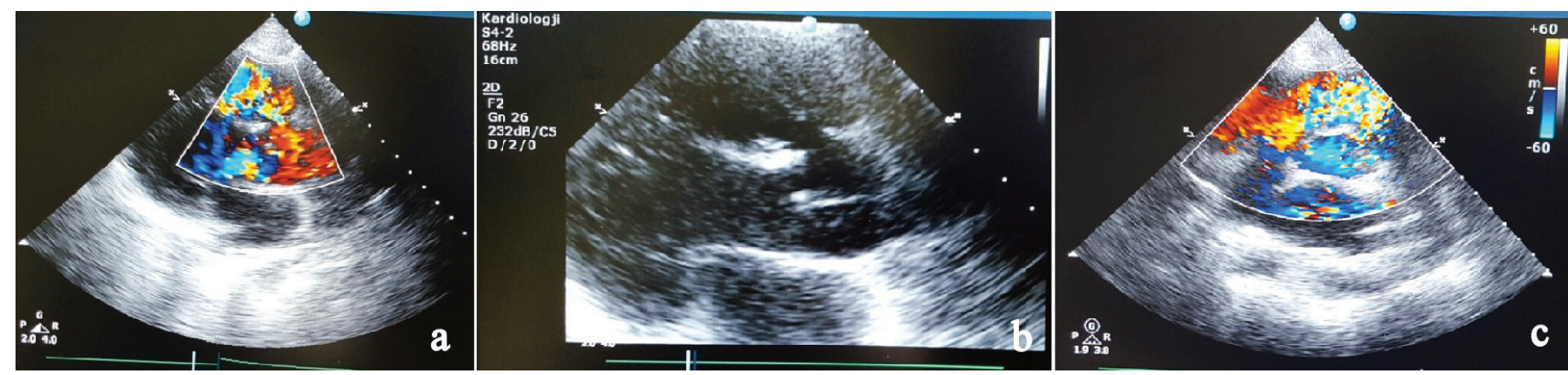

Figure 2. (a) Color-Doppler at parasternal long axis view showing blood flow through the aortic window, however there is no evidence of color flow through ventricular septum. (b) The 2D parasternal long axis view depicting the aortic window. (c) Parasternal short axis view with color-Doppler revealing aortopulmonary communication as well as redirection of a considerable amount of aortic blood to the right ventricle due to pulmonary regurgitation. 


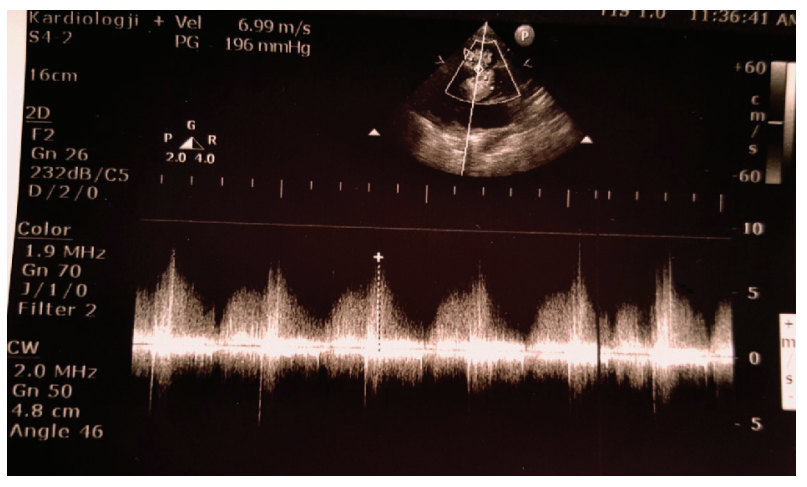

Figure 3. Doppler image showing high velocity flow, around $7 \mathrm{~m} / \mathrm{s}$, through the aortopulmonary window.

of the great arteries and so forth $[10,11]$.

Limitation of this case presentation is that cardiac catheterization and magnetic resonance imaging (MRI) have not been performed to confirm the diagnosis, although echocardiography is a reliable tool for diagnosing aortopulmonary window.

\section{Conclusions}

This is an exceptional rare case of an adult with aortopulmonary window without symptoms or signs of heart failure and pulmonary hypertension. Pulmonary artery regurgitation may serve as a saviour in this rare asymptomatic adult patient with aortopulmonary window, since a large amount of blood that enters the pulmonary trunk from the aorta redirects toward the right ventricle thus not overloading the pulmonary vasculature. Ventricular tachycardia may be the sole clinical presentation in an adult patient with aortopulmonary window and moderate pulmonary window.

\section{Acknowledgments}

We would like to thank all the medical personnel of Cardiology Clinic that were involved in diagnosing and treating this patient.

\section{Financial Support}

None.

\section{Conflict of Interest}

The authors declare that they have no conflict of interest.

\section{References}

1. Aggarwal SK, Mishra J, Sai V, Iyer VR, Panicker BK. Aortopulmonary window in adults: diagnosis and treatment of late-presenting patients. Congenit Heart Dis. 2008;3(5):341-346.

2. Tkebuchava T, von Segesser LK, Vogt PR, Bauersfeld U, Jenni R, Kunzli A, Lachat M, et al. Congenital aortopulumonary window: diagnosis, surgical technique and longterm results. Eur J Cardiothorac Surg. 1997;11(2):293297.

3. Alkumaim M, Al-Fayez M, Munibari A-N. The surgical treatment of aortopulmonary window in Yemeni adolescents and adults. Heart Mirror J. 2010;4:217-219.

4. Kervancioglu S, Soydinc S, Davutoglu V, Kervancioglu R, Sirikci A, Bayram M. Aortopulmonary window: a rare adult case demonstration by echocardiography, MRI, CE-MRA and angiography. Cardiovase Intervent Radiol. 2004;27(2):175-178

5. Giamberti A, Abella R, Consuegra Llapur E, Raweh A, Cirri S, Frigiola A. Successful surgical treatment of congenital aortopulmonary window in an adult patient. Case Rep Cardiol. 2011;2011:505216.

6. El Haouati R, Boukaidi Y, Zouizra Z, Boumzebra D. Aortopulmonary window associated with an ascending aorta aneurysm in an adult. J Tehran Heart Cent. 2015;10(3):156-158.

7. Shimazaki Y, Blackstone EH, Kirklin JW. The natural history of isolated congenital pulmonary valve incompetence: surgical implications. Thorac Cardiovasc Surg. 1984;32(4):257-259.

8. Chaturvedi RR, Redington AN. Pulmonary regurgitation in congenital heart disease. Heart. 2007;93(7):880-889.

9. Koch AM, Hammersen G, Ruffer A. Aortopulmonary window. Eur Heart J. 2012;33(10):1200.

10. Barnes ME, Mitchell ME, Tweddell JS. Aortopulmonary window. Semin Thorac Cardiovasc Surg Pediatr Card Surg Annu. 2011;14(1):67-74.

11. Chen CA, Chiu SN, Wu ET, Lin MT, Wang JK, Chang CI, Chiu IS, et al. Surgical outcome of aortopulmonary window repair in early infancy. J Formos Med Assoc. 2006;105(10):813-820. 